\title{
Critical Thinking and Willingness to Communicate among EFL Students
}

\author{
Ahmad Yaghoubi \\ Department of ELT, Roudehen Branch, Islamic Azad University, Roudehen, Iran
}

\begin{abstract}
The purpose of the study has been to determine the existence of any significant relationship between willingness to communicate as a determining factor in language learning and critical thinking and its psychological constructs. The five psychological levels of critical thinking are inference ability, recognizing assumption ability, deduction ability, interpretation ability and argument evaluation ability. There were two instruments implemented so as to obtain as valid data as possible. First, Willingness to Communicate Questionnaire (WTCQ) was adapted from MacIntyre, Baker, Clément and Conrod (2001) to measure students' willingness to communicate. The second instrument was Critical Thinking Questionnaire (CTQ) which was adapted from Watson \& Glaser (1994), and it was intended to gauge critical thinking and the related psychological constructs. The sample of the study included 360 BA English students who were selected based on the multistage random sampling from the English students at Islamic Azad University branches of Tehran province. The research has been conducted based on a descriptive correlational study which resulted in the existence of significant positive correlation between all psychological levels of critical thinking and willingness to communicate. Moreover, critical thinking as a major variable was also found significantly correlated with willingness to communicate.
\end{abstract}

Index Terms - willingness to communicate, critical thinking, inference making, recognition of assumptions, deduction, interpretation, evaluation of arguments

\section{INTRODUCTION}

According to cognitivists, learning is a cognitive process in which learners add new concepts to their previous knowledge. According to this theory, language learning is also a process that needs thinking. For this reason, meaningful learning and problem solving are emphasized in recent methodologies of language teaching. This process of thinking, problem solving and raising logical questions which leads to a proper evaluation, correct beliefs, or appropriate actions is called critical thinking (CT). Pennycook (1996) defined critical thinking as an improvement in learning from memorizing and repeating to a continuously developing process of discovering, asking logical questions and restating ideas. And according to Scriven and Paul (2004, p.1), critical thinking is the mentally well-organized manner of "actively and skillfully conceptualizing, applying, analyzing, synthesizing, and evaluating information obtained through observation, experience, reflection, reasoning, or communication, which leads to an accurate and proper belief or action". Moreover, critical thinking is also defined as a kind of thinking about different subjects, contents, and problems that the thinker increases the quality of his or her cognition by skillfully using the innate capability of cognition and implanting rational standards to organize them (Paul, Fisher and Nosich, 1993).

Five sub-area of critical thinking are identified which can assess critical thinking ability comprehensively. The first area is inference making, which is defined as "discriminating among degrees of truth or falsity of inferences drawn from given data." The second area is recognition of assumptions, and is defined as "recognizing unstated assumptions or presuppositions in given statements or assertions." The third area is deduction, which means "determining whether certain conclusions necessarily follow from information in given statements or premises." The fourth area is interpretation, which is "weighing evidence and deciding if generalizations or conclusions based on the given data are warranted." And the last area is evaluation of arguments, which is "distinguishing between arguments that are strong and relevant and those that are weak or irrelevant to a particular question at issue" (Watson \& Glaser 1994, pp. 9-10).

Based on the above definitions, it can be found that critical thinking has been frequently considered as an influential factor in learning. And many studies supported the idea of teaching critical thinking in different sciences including English teaching. And much of this owes to the claim that CT can improve learners' thinking and cognition.

On the other hand, based on constructivism, cognition and communication are considered interrelated. And willingness to communicate (WTC) can be taken as the one which triggers cognition and thinking. WTC is well-defined as "readiness to enter into discourse at a particular time with a specific person or persons using an L2" (MacIntyre, Clement, Dornyei, \& Noels, 1998, p. 547). Thus, the higher level of WTC among language learners can increases the opportunity of using L2 both inside and outside of the classroom (MacIntyre, Clement, Dornyei, \& Noels, 1998). Riasati \& Noordin (2011) referred to the same point of view and claim that the aim of modern language teaching is motivating language learners to use the target language for communication both inside and outside of the classroom.

McCroskey (1992) stated some items to assess willingness to communicate among second language learners such as, public speaking, talking in meetings, group discussions, and interpersonal conversations. He also identified different 
types of receivers such as stranger, acquaintance, and friend which can affect the level of ETC. And these different types are defined according to the points that the language learners achieve based on the WTC scale.

To focus on the significance of the study, it can be discussed that thinking critically about language learning and answering to questions like why a new language should be learnt and how communication can be helpful in the process of language learning may accelerate this process more effectively. And this can be done through increasing the level of willingness to communicate among the second language learners which motivates them to use the target language communicatively, and increase the experience of using it in authentic contexts. The results of the current study can also help find out possible means of improving willingness to communicate among second language learners. And all these can be supported by the major theory that the ultimate goal of learning a second or foreign language is having the ability to use the target language for communication.

The present study is aimed at investigating the relationship between critical thinking and willingness to communicate among university students who were studying English as a foreign language. And this study can be pursued by other practical studies to find out whether teaching critical thinking to the L2 learners can affect the level of willingness to communicate among them.

Like any other study, the present study was also bound by several delimitations imposed by the researcher to guarantee more reliability and validity of the study, and it was also faced a number of limitations imposed from outside. As for the delimitations, this study was exclusively conducted on the Iranian EFL university students who studied English as a foreign language in Islamic Azad University in Tehran province. And concerning the limitations, because of the large number of population in this study, simple random sampling was not possible, and cluster multistage random sampling method was used instead.

\section{REVIEW OF THE RELATED LITERATURE}

\section{A. Critical Thinking $(C T)$}

Today, critical thinking is a fashionable expression in psychological, philosophical and educational fields of study. In general, critical thinking is the familiar method of scientific investigation which contains some steps. For this process, first we have the research question and the relevant hypothesis in mind, then the data collection process is conducted, the hypothesis is verified, and finally the conclusion is elicited from the result (Schafersman, 1991). Thus, it can be claimed that all of the skills of scientific investigation are matched by critical thinking. Therefore, according to Schafersman (1991), critical thinking is nothing more than scientific method used in everyday life by common people rather than in particular fields of study. In other words, critical thinking is scientific thinking which is the ability to think reliably and responsibly and make some decisions that affect someone's life.

According to Nickerson (1987, as cited in Schafersman, 1991), a good critical thinker can be defined in terms of knowledge, abilities, attitudes, and the usual behaviors. Schafersman (1991) also stated some characteristics of a critical thinker as: having the ability to use evidence skillfully and fairly, organizing and stating thoughts logically, realizing valid and invalid conclusions, recognizing the differences between reasoning and rationalizing, trying to predict the possible conclusions of alternative actions, having the ability to learn autonomously, applying problem-solving methods in the broader contexts, trying to challenge own thoughts and find the assumptions that are critical to those thoughts and the inferences of the thoughts, being sensitive about the differences between the validity of an idea and the its strength, knowing that our understanding is always limited, being aware of the fallibility of own opinions, realizing that assumptions can be affected by bias, and being conscious about judging evidence according to personal preferences.

Elder and Paul (1996) stated a stage theory in order to be a critical thinker and claimed that learners should pass six different stages to develop the critical thinking skills. These stages are: the unreflective thinker, the challenged thinker, the beginning thinker, the practicing thinker, the advanced thinker, and the accomplished thinker.

Moreover, Duron, Limbach and Waugh (2006) stated a 5-step model to move students toward critical thinking and claimed that this model is a framework which can be used in any classroom or educational setting to help students increase critical thinking skills. Figure 1 shows the 5-step model stated by Duron et al. (2006). 


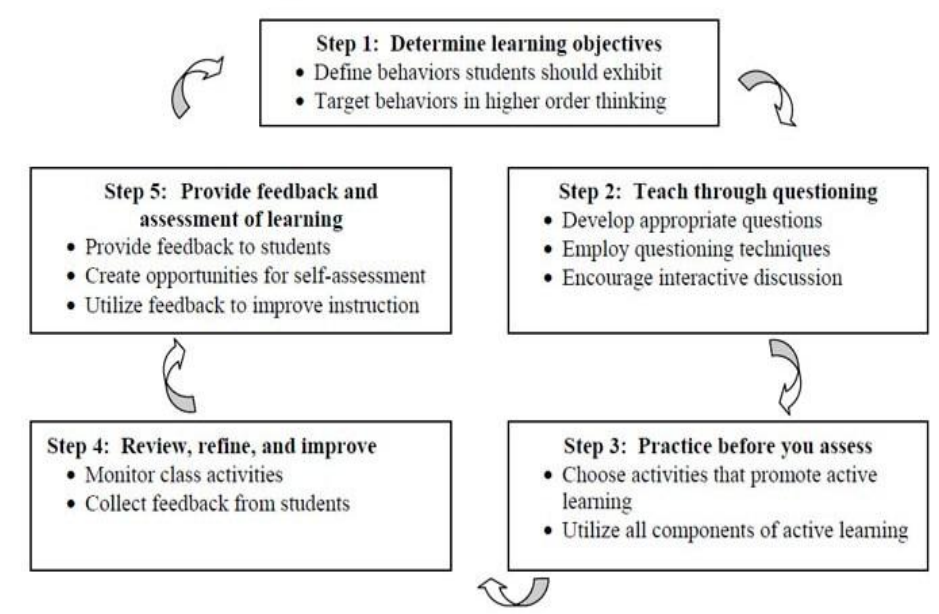

Figure 1. The 5-step model to move students toward critical thinking (Duron et al., 2006)

\section{B. Willingness to Communicate (WTC)}

Willingness to communicate is well-defined as "readiness to enter into discourse at a particular time with a specific person or persons using an L2” (MacIntyre, et al., 1998, p. 547). For the first time, McCroskey and Baer (1985, as cited in Ghonsooly, Hosseini Fatemi, \& Khajavy, 2014) proposed the notion of WTC in first language. They stated that human being gradually acquires language by communicating with other people. However, Lately, WTC has been reinterpreted as a situational variable which can be changed according to the context in second or foreign language (MacIntyre et al., 1998).

WTC is different when considered in the second language. In fact, In an L2 context, communicative competence is different among different people. It is stated that WTC in second language "can range from almost no L2 competence $(0 \%)$ to full L2 competence (100\%)" (MacIntyre et al., 1998, p. 546). Therefore, there should be some variables involved. It is stated that WTC in second language is related to both characteristic traits and external variables. Some variables such as "state of communicative self confidence, desire to communicate with a specific person; selfconfidence, intergroup and interpersonal motivation; communicative competence, social attitudes, and intergroup attitudes; and personality and intergroup climate" can affect WTC in a second language context (MacIntyre et al., as cited in Ghonsooly, Khajavy, \& Asadpour, 2012, p.198).

According to MacIntyre (2007), some people choose to speak and the others remain silent when they have opportunity to use their second language. It means that WTC shows the psychological readiness to use the second language. And it is usually considered as the main reason of being aggressive in using the second language $(\mathrm{Yu}, \mathrm{Li}, \&$ Gou, 2011). This refers to a willingness to communicate which generates the opportunities to communicate in the target language. "Being willing to communicate is part of becoming fluent in a second language, which often is the ultimate goal of L2 learners" (MacIntyre and Doucette, 2010, p. 1).

MacIntyre et al. (1998) suggested a conceptual pyramid model to represent the individual differences in making communication in the second language. Having communication with specific people at a specific time is at the top of the pyramid. Therefore, it means that WTC is considered as the final step before opening the conversation in the second language. The other parts of the model maintain the goal of starting communication according to the specific situation. The conceptual pyramid model refers to situations that there is a specific person who starts communication with others with the desire and self-confidence to talk to them. In many cases this desire is related to affiliation and control motives. Affiliation motives are related to people who are somehow attractive or visited frequently, such as friends. On the other hand, control motives are related to any condition that people look for to influence each other. 


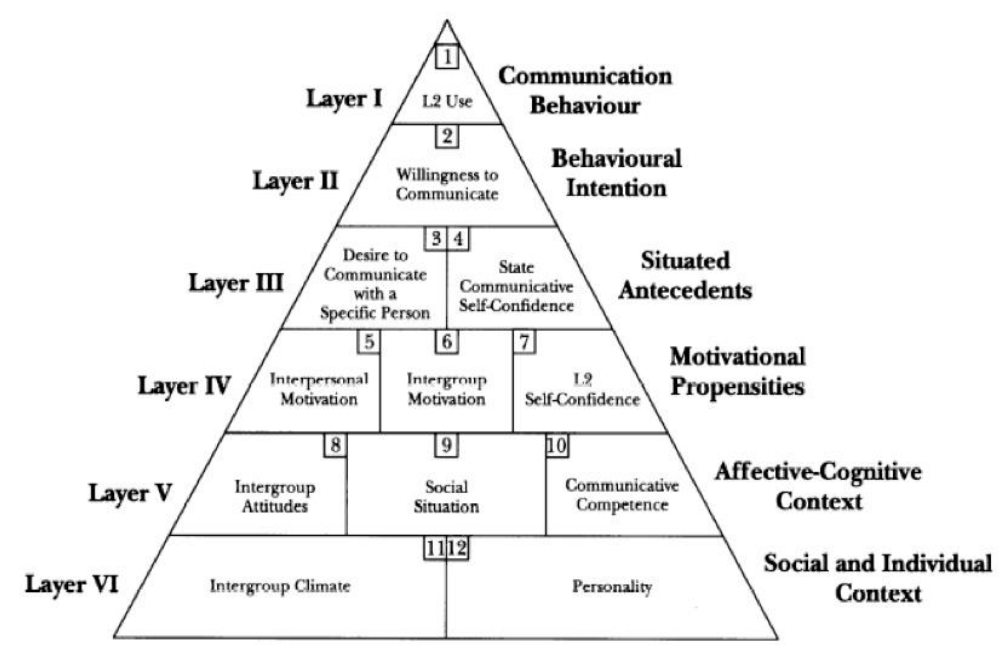

Figure 2. Heuristic model of variables influencing WTC (MacIntyre et al. 1998)

\section{The Possible Relationship between CT and WTC}

Today, many people in Iran are trying to learn English as a foreign language for different purposes such as, business, study and travel. It means that they need English in order to communicate with other people. But, many Iranian EFL students have been faced a lot of problems while speaking English and many of them cannot speak fluently and appropriately. Therefore, based on the above mentioned ideas, WTC can be seen as an effective variable on improving communicating in English, and this variable might be deeply related to critical thinking which is considered essential in learning.

According to what mentioned above, the present study tried to investigate the relationship between the critical thinking and willingness to communicate in Iran. Moreover, the researcher has intended to examine the magnitude of possible correlations between the five psychological constructs of critical thinking (inference ability, interpretation ability, deduction ability, recognizing assumption ability and argument evaluation ability) and the learners' willingness to communicate. Accordingly, the following null research hypotheses were proposed:

1. There is no significant relationship between inference ability and willingness to communicate among English language students at IAU branches of Tehran province.

2. There is no significant relationship between interpretation ability and willingness to communicate among English language students at IAU branches of Tehran province.

3. There is no significant relationship between deduction ability and willingness to communicate among English language students at IAU branches of Tehran province.

4. There is no significant relationship between recognizing assumption ability and willingness to communicate among English language students at IAU branches of Tehran province.

5. There is no significant relationship between argument evaluation ability and willingness to communicate among English language students at IAU branches of Tehran province.

6. There is no significant relationship between critical thinking and willingness to communicate among English language students at IAU branches of Tehran province.

\section{METHOD}

\section{A. Participants}

The target population of the study included the subset of the English Language student population at Islamic Azad University branches of Tehran province. They were both male and female, and doing BA (Bachelor of Arts) in the field of English language. The samples were selected based on a multistage area random sampling that is also known as cluster sampling. Due to the research requirements, three branches in Tehran province were selected randomly, namely Roudehen, Eslamshahr and Tehran Shomal. Second, eight classes were selected from each of these university branches. Third, sixty male and sixty female English senior students were randomly selected from the classes of each branch to have 360 participants, and the instruments of the study were administered to these students.

It is pertinent to mention that some necessary measures were taken for the selection of participants in order to increase the internal validity of the results by eliminating some intervening variables. Firstly, the same proportion of male and female students was selected. This decision helped the researcher to eliminate the gender factor as an intervening variable. Secondly, only senior English students with reasonable English backgrounds took part in this study. By seniors, the researcher has referred to those students who were at the last two years of BA. As a matter of fact, the researcher preferred to use senior student who were able to answer the questionnaires of the study which were in 
English. And as the last one, the age of the participants was also limited between 20 and 30 . This age limitation might have been fruitful to the research due to the fact that the age factor might also serve as an intervening variable.

All the subjects were informed of the sensitivity of the study to cooperate with extensive care, and were well informed that taking part in the research can be a good estimation of their own willingness to communicate and critical thinking ability. And those students who preferred to write their names on the answer sheets were informed of the results on the Willingness to Communicate Questionnaire (WTCQ) and the Critical Thinking Questionnaire (CTQ) within two weeks.

Fortunately, most of the subjects were truly active participants in answering both instruments cooperatively and with care. Finally, 344 students cooperated with the researcher to the desired extent, and the data analysis of the study was based on the data collected from them. Moreover, the authorities and teachers in the universities were very courteous, kind and cooperative in the process of data collection.

\section{B. Instruments}

There were two instruments implemented in the research so as to obtain as valid data as possible. First, WTCQ was adapted from MacIntyre, Baker, Clément and Conrod (2001) to measure students' willingness to communicate. The questionnaire was operationalized in four basic skill areas listening, speaking, reading and writing to indicate how much willing they would be to communicate. The scale includes 27 items and the range is 1 to 5 ( $1=$ almost never willing, 2 = sometimes willing, 3 = willing half of the time, $4=$ usually willing, and $5=$ almost always willing). Regarding the reliability of the instrument, in the following quotation, Zarrinabadi and Abdi (2011) referred to the reliability estimation of the questionnaire developer and the one they did to estimate the reliability in the context of Iran.

MacIntyre et al. (2001) report this scale to be a valid and reliable one (alpha levels indicate reliability estimates): speaking ( 8 items, $\alpha=.81$ ), comprehension (5 items, $\alpha=.83$ ), reading (6 items, $\alpha=.83$ ), and writing $(8$ items, $\alpha=.88$ ). The alpha reliability estimates for this instrument in the current study are as follows: speaking (8 items, $\alpha=.78)$, comprehension (5 items, $\alpha=.79$ ), reading (6 items, $\alpha=.85$ ), and writing ( 8 items, $\alpha=.85$ ). (Zarrinabadi $\&$ Abdi, 2011, p. 208)

The second instrument was Critical Thinking Questionnaire (CTQ) which was intended to tap into critical thinking in general. Sharp and Herbert (2003) present the following description on the instrument based on the Watson-Glaser Critical Thinking Appraisal derived from the WGCTA Manual. The CTQ is a 28-item multiple-choice format measure. Each item has only one correct answer. Further, the CTQ required less time to be answered than other existing critical thinking measures. The CTQ was developed to measure five specific sub-areas of critical thinking: inference making, recognition of assumptions, deduction, interpretation and evaluation of arguments (Watson \& Glaser, 1994).

\section{RESUltS}

In the core of this study, the researcher has intended to examine the magnitude of possible correlations between critical thinking and its five psychological constructs (inference ability, interpretation ability, deduction ability, recognizing assumption ability and argument evaluation ability) and the learners' willingness to communicate in order to examine the research hypotheses.

Since the present data were analyzed through the parametric tests of Pearson correlation, the relevant assumptions were met. The data were measured on the interval scale. The subjects were independent. And the data were normally distributed with skewness of -0.145 and kurtosis of -0.171 for CT and skewness of -0.97 and kurtosis of -0.724 for WTC. The values are within the ranges of $+/-1.96$.

In order to answer the first research question, the researcher correlated the students' scores of the inference ability section of the Critical Thinking Questionnaire (CTQ) with the scores of the Willingness to Communicate Questionnaire (WTCQ). The obtained correlation coefficient between the two variables stood at 0.515 which was positive and significant at the 0.05 level. Therefore, the null hypothesis which stressed the nonexistence of any significant relationship between inference ability and willingness to communicate was rejected.

To verify the second research question, the correlational analysis was applied to the relevant data. And as the finding, the correlation between interpretation ability and willingness to communicate was positive and significant at the 0.05 level. The amount of correlation coefficient came out to be 0.503 . Hence, in consequence of the result, the second null hypothesis was also rejected which claimed the nonexistence of any meaningful relationship between the two variables.

Then with the intention of deciding on the third hypothesis, the gathered data were examined to search for any significant relationship between the deduction ability dimension of critical thinking and willingness to communicate. The r-observed was found to be 0.331 which was positive, low but significant. Therefore, based on the result, the null hypothesis which claimed the nonexistence of any significant relationship between the variables was rejected.

The fourth research hypothesis of the study was intended to examine the correlation between recognizing assumption ability and willingness to communicate. The correlation between these two factors was positive and significant at the 0.05 level. The amount of correlation coefficient came out to be 0.406 . Hence, in consequence of the result, the fourth null hypothesis was also rejected.

Then in order to answer the fifth research question, the gathered data were examined to search for any significant relationship between the argument evaluation ability dimension of critical thinking and willingness to communicate. 
The r-observed was found to be 0.420 which was positive, low but significant. Therefore, based on the result, the null hypothesis which claimed the nonexistence of any significant relationship between the variables was rejected.

The sixth research question investigated the possible significant correlation between the major variable, critical thinking and willingness to communicate. The correlation between these two factors was positive and significant at the 0.05 level. The amount of correlation coefficient came out to be 0.435 . Hence, in consequence of the result, the sixth null hypothesis was also rejected which claimed the nonexistence of any meaningful relationship between the two major variables.

\section{DISCUSSION}

To look at other investigations and the related findings, mostly a two way connection were stressed upon. For instance, Nussbaun (2002) suggested that participation in oral discussions develops students' critical thinking skills. This statement is in line with the findings of the present study and reinforces the presence of meaningful relationship between willingness to communicate and critical thinking.

From another point of view, Scholars like Datar, Garvin and Cullen (2010) presented the idea that thinking critically and communicating clearly are closely related, and again somehow this reinforces the findings of the present study. To support this idea Halpern (1998) found that college graduates who demonstrate an advanced ability to think critically could communicate more effectively.

Furthermore, Quitadamo and Kurtz (2007) investigated the factors affecting the written communication and interestingly they found that thinking critically is a significant variable which can affect the written communication positively among biology students.

\section{CONCLUSION}

\section{A. Findings}

As mentioned, the main problem which triggered the researcher to open the study was considering critical thinking as an individual difference which enables the language learners to communicate better due to the fact that willingness to communicate can be triggered by thinking critically. Through this investigation, the null hypotheses which stressed the nonexistence of any significant relationships between the psychological constructs of critical thinking and willingness to communicate at an EFL context were investigated.

In the course of these investigations, significance of positive and low/moderate correlations between the psychological constructs of critical thinking and willingness to communicate were found. Thus, in the light of the findings, the six null hypotheses of the study were rejected and critical thinking was found related to willingness to communicate. Table 1 depicts the finding of the study at a glance.

TABLE I.

FINDINGS OF THE STUDY

\begin{tabular}{|l|l|l|}
\hline Hypotheses & Correlation & Conclusion \\
\hline \hline One & $0.515^{*}$ & Rejected \\
\hline Two & $0.503^{*}$ & Rejected \\
\hline Three & $0.331^{*}$ & Rejected \\
\hline Four & $0.406^{*}$ & Rejected \\
\hline Five & $0.420^{*}$ & Rejected \\
\hline Six & $0.435^{*}$ & Rejected \\
\hline \multicolumn{2}{|l|}{ * Correlation is significant at the 0.05 level. }
\end{tabular}

\section{B. Implications}

Based on the findings of the present study and with the help of the future applied studies which can stress upon the effectiveness of critical thinking on willingness to communicate, curriculum developers can be advised to implement critical thinking courses in order to foster willingness to communicate among foreign language learners.

Moreover, Syllabus designers can also use critical thinking tasks which can trigger willingness to communicate. There is no doubt where willingness to communicate gets increased communication and language learning can also be improved.

Teachers should also be informed on the practicality and importance of critical thinking tasks to invest enough time and energy on them to have better communication and better language learning in their classes.

\section{REFERENCES}

[1] Datar, S. M., D. A. Garvin \& P. G. Cullen. (2010). Rethinking the MBA. Business education at the crossroads. Boston: Harvard Business Press.

[2] Duron, R., B. Limbach, \& W. Waugh. (2006). Critical thinking framework for any discipline. International Journal of Teaching and Learning in Higher Education 17.2, 160-166. 
[3] Elder, L. \& R. Paul. (1996). Critical thinking development: A stage theory (no date). www.criticalthinking.org/pages/criticalthinking-development-a-stage-theory/483 (accessed 2/4/2015).

[4] Ghonsooly, B., A. Hosseini Fatemi \& G. H. Khajavy. (2014). Examining the relationships between willingness to communicate in English communication confidence and classroom environment. International Journal of Research in Educational Technology 3.1, 63-71.

[5] Ghonsooly, B., G. H. Khajavy \& S. F. Asadpour. (2012). Willingness to communicate in English among Iranian non-English major university students. Journal of Language and Social Psychology 31, 197-212.

[6] Halpern, D. (1998). Teaching critical thinking for transfer across domains: Dispositions, skills, structure training, and metacognitive monitoring. American Psychologist 53, 449-455.

[7] MacIntyre, P. (2007). Willingness to communicate in the second language: Understanding the decision to speak as a volitional process. The Modern Language Journal 91.5, 564-576.

[8] MacIntyre, P. \& J. Doucette. (2010). Willingness to communicate and action control. System 38.2, 161-171.

[9] MacIntyre, P., R. Clement, Z. Dornyei \& K. Noels. (1998). Conceptualizing willingness to communicate in a L2: A situational model of L2 confidence and affiliation. The Modern Language Journal 82, 545-562.

[10] MacIntyre, P., S. C Baker, R. Clement, \& S. Conrad. (2001). Willingness to communicate, social support, and languagelearning orientations of immersion students. Studies in Second Language Acquisition 23, 369-388.

[11] McCroskey, J. C. (1992). Reliability and validity of the willingness to communicate scale. Communication Quarterly 40.1, 1625.

[12] Nussbaun, E. M. (2002). How introverts versus extroverts approach small-group argumentative discussions. The Elementary School Journal 102.3, 183-197.

[13] Paul, R., A. Fisher \& G. Nosich. (1993). Workshop on critical thinking strategies: Foundation for critical thinking. CA: Sonoma State University.

[14] Pennycook, A. (1996). Borrowing others' words: Text, ownership, memory, and plagiarism. TESOL quarterly 30(2), 201-230.

[15] Quitadamo I. J. \& M. J. Kurtz (2007). Learning to improve: Using writing to increase critical thinking performance in general education biology. CBE Life Sci. Educ 6, 140-154.

[16] Riasati, M. J. \& N. Noordin. (2011). Antecedents of willingness to communicate: A review of literature. Studies in Literature and Language 3.2, 74-80.

[17] Schafersman, S. D. (1991). An introduction to critical thinking (no date). http://www.freeinquiry.com/critical-thinking.html (accessed 7/4/2015).

[18] Scriven, M. \& R. Paul. (2004). The critical thinking community (no date). http://www.criticalthinking.org/aboutCT/definingCT.shtml (accessed 8/4/2015).

[19] Sharp, I. R. \& J. D. Herbert. (2003).The role of critical thinking skills in practicing psychologists' theoretical orientation and choice of intervention techniques. Philadelphia, PA: Drexel University.

[20] Watson, G. \& E. M. Glaser. (1994). Watson-Glaser critical thinking appraisal-manual. S. San Antonio, TX: Psychological Corporation.

[21] Yu, H., H. Li \& X. Gou. (2011). The personality-based variables and their correlations underlying willingness to communicate. Asian Social Science 7.3, 253-257.

[22] Zarrinabadi, N. \& R. Abdi. (2011). Willingness to communicate and language learning orientations in Iranian EFL context. International Education Studies 4.4, 206-214.

Ahmad Yaghoubi is an assistant professor in TEFL at the Department of English Language Teaching of Roudehen Islamic Azad University. His areas of interest include issues in foreign and second language teaching and learning. 